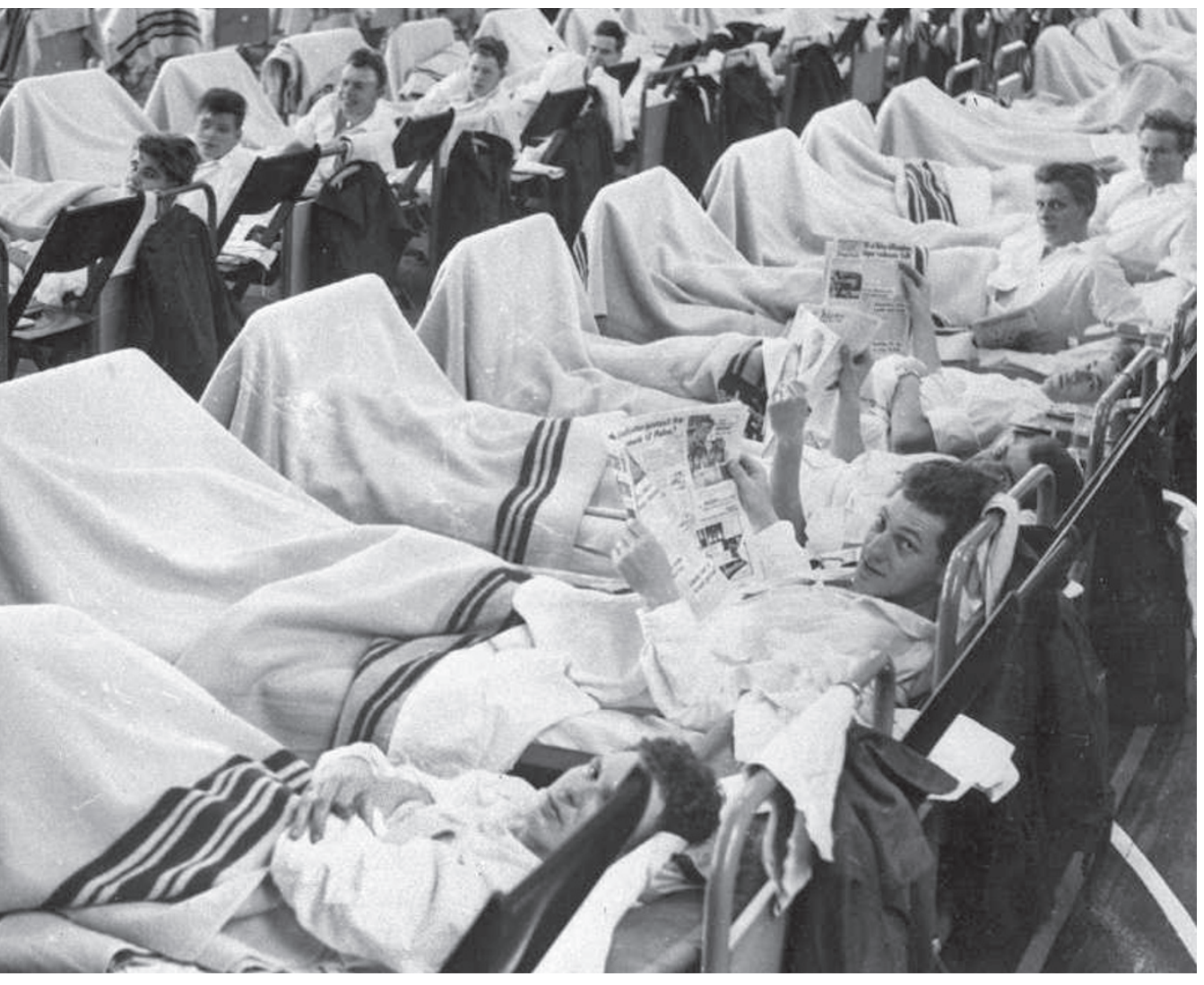

Viral overload: the 1957 flu pandemic affected millions of people around the world.

ways, points out Eric Mortensen of the Audie L. Murphy Veterans hospital in San Antonio, Texas. They need to be replicated with a much larger number of mice, and examining other potential pathways, says Mortensen.

Clark even asserts that "if the same outcomes had been repeated at $n=15$, the statistics would show the opposite of what Webster's group claimed," he says. However, Rachelle Salomon, the lead author of the study, says "large numbers of mice would be ideal, but due to our experience with these viruses, I am confident with the result and conclusions". The groups were small because the experiments needed to be done in laboratories with an approved biosafety level of at least 3 (the maximum is 4), she explains. Because Australia has different standards, Clark was able to use level 2 facilities.

Statins - another lipid-lowering class of drug with anti-inflammatory effects - might be a better bet than gemfibrozil, says Mortensen, who has papers in the press showing that these drugs lower the number of deaths from pneumonia. And then there is a preliminary analysis ${ }^{4}$ of 20,000 patients older than 50 years enrolled in the University Medical Center Utrecht primary-care network in the Netherlands by Eelko Hak and his colleagues at the university. They found that during flu epidemics, people who took statins were $28 \%$ less likely to develop res- piratory disease and 51\% less likely to die from any cause than were those who did not take the drugs. Another, case-control study ${ }^{5}$ of 130,000 patients also found that current use of statins lowered mortality from pneumonia.

But Frederick Hayden of the World Health Organization's global influenza programme says that pandemic flu involves protracted viral replication, often over weeks, so using immune drugs when viral replication is high could do more damage than good. A more sensible idea might be to study joint treatments with immune modulators and antivirals, he says.

But definitive answers can only come from clinical trials done immediately after the onset of a pandemic, says Peter Openshaw of Imperial College London. "We need to be able to plan ahead and set up trial protocols, but that's not easy to do when we don't know when an epidemic may strike."

Declan Butler

1. Budd, A. et al. Antimicrob. Agents Chemother. 51, 2965-2968 (2007).

2. Salomon, R., Hoffmann, E. \& Webster, R. G. Proc. Natl Acad. Sci. USA 104, 12479-12481 (2007).

3. Szretter, K. J. et al. J. Virol. 81, 2736-2744 (2007).

4. Hak, E., Verheij, T., van Essen, G., Bonten, M. J. M. \& Hoes, A. 16th European Congress of Clinical Microbiology and Infectious Diseases, Nice, abstr.; www.blackwellpublishing. com/eccmid16/abstract.asp?id=49073 (2006).

5. Schlienger, R. G., Fedson, D. S., Jick, S. S., Jick, H. \& Meier, C. R. Pharmacotherapy 27, 325-332 (2007).

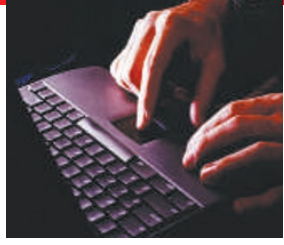

THE GREAT BEYOND

Check out our new blog, rounding up science stories from around the world. http://blogs. nature.com/news/ thegreatbeyond/

\section{Flying insects threaten to deafen Japan}

A cicada known as the kumazemi is descending on Japan en masse, deafening the citizens and wreaking havoc on the country's fibre-optic system. The 6- to 7-centimetre-long black cicada (Cryptotympana facialis) inhabits western Japan and subtropical regions of eastern Asia. This August is expected to be the largest and noisiest cicada summer in the insect's four-year cycle.

Surveys of the shells shed by maturing cicadas at a park in Osaka, carried out by Shigehiko Shiyake, curator of the Osaka Museum of Natural History, and Eiji Numata, a biologist at Osaka University, show that the cicada population increases every year for four years, after which it returns to base level and the cycle restarts. From the past three years' data, the scientists calculate that this year will be the four-year peak, with nearly 2.5 times as many cicadas as in 2006. The noise level is also set to climb. Measured at 90.4 decibels at another Osaka park last year, this year the same spot is expected to hit 94 decibels - decibels follow a logarithmic scale, so that's more than double the volume. Prolonged exposure to this level of noise can cause deafness.

The kumazemi are also cutting households off from their Internet. Apparently mistaking fibre-optic cables for withered branches, they have been punching their one-millimetre-diameter ovipositors into the cables and laying eggs. In at least 1,000 cases over the past two years, the cicadas have either severed the cable or opened up a hole, allowing water to seep in. The Osaka-based Nippon Telephone and Telegraph West Corporation has responded by creating new cables that lack the grooves that the cicadas target with their ovipositors and by adding another protective plastic layer to the cable. David Cyranoski

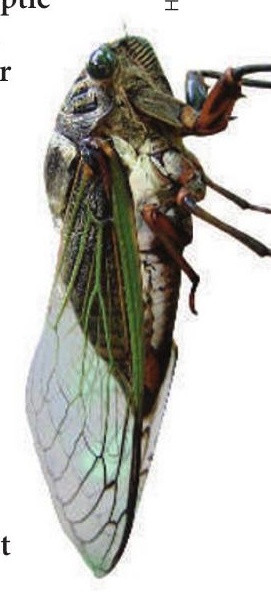

$\square$ 